\title{
Materialism and Consumerism Through Urban Social Lifestyle In The Context of Shopping Malls: Malaysian Perspective
}

\author{
Mohammad Khizal Saat ${ }^{1}$, Shahrul Anuar Shaari ${ }^{2}$, Tetriana Ahmad Fauzi ${ }^{3}$ \\ ${ }^{1}$ Fine Art Department, School Of The Arts, Universiti Sains Malaysia, Penang, Malaysia \\ ${ }^{2}$ Fine Art Department, School Of The Arts, Universiti Sains Malaysia, Penang, Malaysia \\ ${ }^{3}$ Fine Art Department, School Of The Arts, Universiti Sains Malaysia, Penang, Malaysia \\ mkhizal@usm.my (Mohammad Khizal Saat1), shahrul_anuar@usm.my (Shahrul Anuar Shaari), tetriana_af@yahoo.com (Tetriana \\ Ahamd Fauzi)
}

\begin{abstract}
This research is carried out to study the values and lifestyle and culture of the city dwellers through the principles of materialism and consumerism by giving more emphasize on the values of consumers as well as on the values which can be identified at the main shopping malls in Kuala Lumpur which in turn directly impacts the formation of social lifestyle at the city. A recent study places Malaysia at the fourth place whereby the people comes to shopping malls on a frequency of twice every week, roughly at the same level of the neighbouring countries like Singapore, Thailand, and Hong Kong, for the purpose of casual, entertainment, and leisure. Through the shopping malls, the social lifestyle culture expression of the current day could be identified and tracked. Basically, coming to the shopping malls for the purpose of shopping or recreation most often would create or stimulate a sense of taste which directly has created an identity and also at the same time has enhanced and developed a better way of living for the city dwellers. This research is carried out to identify and explain on how the culture of urban societies which is apparent in the environment of the shopping malls could directly impact the lifestyle of the city dwellers. Through the methods of field observations or observational research and descriptive analysis, this research it will look into how the shopping malls play its part in creating obsession, emotion, aspiration, as well as creating a system of belief within the community of city dwellers in the wake of developing a daily form of lifestyle. The function of shopping malls as the main contributor in the formation of a new perspective for the reinterpretation of an urban culture lifestyle, indirectly it helps in understanding in a broader term, the meaning of city community and it also to provide an overview of Malaysia shopping malls landscape and their social culture as a whole.
\end{abstract}

Keywords Lifestyle, Culture, Urban, Shopping Malls.

\section{Introduction}

This research investigates the value of lifestyle in ur- ban society through principles of materialism and consumerism through shopping malls within Malay- sian perspective. The research was conducted through the observation on consumer values of consumption within the major shopping malls in Kuala Lumpur. Yusniza K. and Chee Lih, Frankie Lee (2010) stated that "Shopping malls are constantly being upgraded to cater to the increasingly fast-paced and cosmopoli- tan lifestyle of the Malaysian people" (p. 187). In ad- dition they indicated that: "Malaysian shoppers are motivated to visit malls because of the ambience, in- terior design of the malls, convenience, accessibility and promotion. Evidence shows that there is a strong relationship between shopping mall characteristics and actual action of shoppers in visiting shopping malls". (Yusniza K. and Chee Lih, Frankie Lee, 2010, p. 187).
Urban lifestyle forms through the perception and belief towards materialism. It is definitely grounded by the consumerism concept practiced everyday by the society. To understand certain cultures or the way of life, it is necessary to look and identify the lifestyle and the everyday routine in the society or community itself. Urban areas or cities are known to symbolize the unity and combination of varieties influences. It represents and mirrors the value of social culture within it. As stated by Clark (2003), mention that urbanization concept containing some urban lifestyle is a reflection of the pattern that are related to social, economic, behavioral, fashion culture, taste, identity and all of this is part of the aspirations of the people who live in it. Hence, the rapid growth of urban infra- structure such as shopping malls contribute in max- imizing the urban life potential. It does not just pat- ternize the economic structure but also bring the value added for city dwellers. The concept of a center under one roof or one-stop shopping center become more relevance and practical for today society who live within shopping malls, and yet unconsciously it becomes a social therapy to 
the visitors. The social life- style which is collected in one space and connected through several aspect of life. Urban people are keen to seek the satisfaction in living. Through the material and goods as well as with the help from shopping malls as the significant platform moulding the peo- ple's behaviors and habits. Thus, cities and shopping malls are no longer seen as space merely for developing the financial and economic aspect, but as signif- icant symbols of lifestyle for members of the urban society to satisfy an emotional desire, positively re- lated to individual value of life perception.

\section{Research Methodology}

Through the methods of field observations or observational research whereby the active observations enable the researcher to describe existing situations using the five senses, providing a "written photograph" of the situation under study (Erlandson, Harris, Skipper, \& Allen, 1993). Observation methods are useful to researchers in a variety of ways. They provide researchers with ways to check for nonverbal expression of feelings, determine who interacts with whom, grasp how participants communicate with each other, and check for how much time is spent on various activities. Hence with descriptive analysis, this research it will look into how the shopping malls play its part in creating obsession, emotion, aspiration, as well as creating a system of belief within the community of city dwellers in the wake of developing a daily form of lifestyle within Malaysian perspective.

\section{Materialism and Consumerism in Urban Society}

Materialism plays such a huge role in urban living and it mirrors the dreams and the illusions of people who rely on it, in away to satisfy personal needs. Baudrillard (1998, as cited in Dant, T., 1999) remarked that "Strictly speaking the human of the age of affluence are surrounded not so much by other human beings, as they were in all previous ages, but by objects" ( p. 26). Thus, the object which surrounds the human, particularly people who live in urban environment, will blend and mould the people's behavior, thinking, acting and projecting themselves to suit the current and fast-changing urban environment.

The significance of product or object oriented consumption becomes more vital in portraying the group of people or society to identify the obsession towards materialism. It is the primary premise of the construction of identity and personality of society. Object consumption significant in nowadays lives to portray- ing the sense of materialism as state by Baudrillard (1987, as cited in Koch, A. M. \& Elmore, R., 2006) "Everything began with the object, [...] the dream of the object as existing beyond and above exchange and use, above and beyond equivalence..." (p. 10). The existence of materialism can be related to time, space and place towards individuals who consume or use the objects or services. It carries the meaning and cer- tain signs which are significant in interpreting or reading them. It began with an ordinary object and meant to be used for the sake of necessity it turned into popular objects and signs of lifestyle.

Materialism being complemented by consumerism, has become a part of the materialism agenda. Both elements will reveal the value of belief, passion, attitude of the owners of objects. In addition, in fast-growing urban environment with complete facilities, especially the emerging huge, conspicuous and sophisticated shopping malls nowadays being able to cater to the urban society's needs, broaden the choices and open vast possibilities for people to select in order to suit their satisfaction and personal desires. The services and the multiplication of objects provided will definitely change and shape the urban society from time to time in accordance with the current material culture. Marx (1976, as cited in Lloyd, G., 2008) in his remarks once stated that "...describes a commod- ity as an object outside us, a thing that by its proper- ties satisfies human wants of some sort or another. The nature of such wants, whether, for instance they spring from the stomach or from the fancy, makes no difference" (p. 11).

Urban society lifestyle was created and moulded through materialism by giving the emotional value when facing consumerism. It definitely contributed some impact in constructing the image of the commu- nity itself. According to Sheth, J. N. Newman, B. I. \& Gross, B. L. (1991), stressing the emotional or feeling characteristic contributed in shaping the iden- tity in consumption of material goods activity and that "The perceived utility acquired from an alternative's capacity to arouse feelings or affective states. An al- ternative acquires emotional value when associated with specific feelings or when precipitating those feelings. Emotional values are measured on a profile of feelings associated with the alternative" (p. 161). Therefore, the materialistic culture particularly in ur- ban people will use the emotional value in the buying process, owning the desired objects and in the consumption of services. In addition Sheth et al. (1991, as cited in Abdallat et al. (n.d) ) pointed out that the "Consumption emotion refers to the set of emotional responses elicited specifically during product usage or consumption experience, as described either by the distinctive categories of emotional experience and expression" (p. 21).

Materialism and consumerism unconsciously established the huge possibilities significant to urban life style. The opportunities of urban society in projecting satisfaction, obsession, and ego became successful sign that these concepts could mould and shape peoples' mind in urban environments. Nevertheless, both materialism and consumerism succeeded in their roles, receiving the supportive platform of advertising as a significant attribute in promoting the awareness to the community at large especially when their enter shopping malls.

\section{Shopping Malls and Consumers Lifestyle: Malaysian Perspective}

The rapid development in urban infrastructure of shopping malls in Malaysia particularly has provided more space and ability to urban community in con- sumption activities. As 
mention by Aliagha, G. U., Qin, Y. G., Ali, K. N., \& Abdullah, M. N. (2015) "The rapid economic growth, high urbanization rate cou- pled with rising income and globalisation has created a boom market for the development of quality, world- class malls in Malaysia" (p. 15). Hence, in addition the demography change in urban areas which affected the migration of people from rural areas to urban areas could be considered as a key point in attracting the developer to build more shopping malls as ways to support the demand from the community.

According to Raine \& Horne International Zaki + Partners Sdn. Bhd (1995) report, in year of 1960 until 1970', the placement of the shopping center in Klang Valley only concentrated in Kuala Lumpur, due to rapid development of Kuala Lumpur as center for in- dustry and administration compared to other location in Lembah Klang (Aiken Leigh, 1975, Bunnel et al., 2002, as cited in Hussain, M.Y. et al, 2012, p. 131). The laying pattern also influenced by the population density which is high in Kuala Lumpur. Based on sur- vey conducted by Katiman (2010), the urban population of Kuala Lumpur in 1970's was the highest in Klang Valley with 876,873 people compared to other regions (Hussain, M.Y. et al, 2012, p. 131) the popu- lation in Kuala Lumpur continue to increase in years after, and according to the 2010 Population and Housing Census of Malaysia (Census, 2010) con- ducted by Department of Statistic, Malaysia, reported the population in Kuala Lumpur increase up to $1,627,172$ people (Malaysia, B.P.D.P. Malaysian Department of Statistic). The increasing numbers of population thus, significant in contributing towards the development of new shopping malls as strategic location to cater. community needs.

The history of shopping malls development in Kuala Lumpur started in year of 1963 when the Weld Supermarket was built and followed by others such as Emporium Selangor, Globe Silk Store, Yuyi Empo- rium and Batu Road Supermarket. Later, the second phase of shopping malls development occurred in 1973 when the Ampang Park Shopping Centre was built, and Sungei Wang Plaza in 1977 followed by Wisma Central, Sun Complex, Pertama Complex, Wisma MPI and also Angkasaraya. Most of the earli- est shopping malls were built merely for selling common goods and became local community centres compared to today's shopping malls which are pur- posely designed with sophisticated elements. The previous malls did not very much stress on malls en- vironment and entertainment in attracting visitors to sit longer to compare today malls, which is more, en- tertaining, relaxing, and more enjoyment provided by the malls organizer. From 2000 until now, there are lot of changes in the development of shopping malls in Kuala Lumpur. Malaysia have experienced the sprouting of sprawling mega malls in the Malaysian retail scene. Berjaya Times Square with 2.1 million sq. feet of retail space opened to Malaysian shoppers in 2003. Presently the top 6 shopping malls include Berjaya Times Square, Mid-Valley Mall, KLCC, (Figure 1), 1-Utama and Sunway Pyramid. "The malls have created a new lifestyle and a change in consumer behaviour and Malaysians have become more de- manding in their shopping expectations" (Aliagha, G. U., Qin, Y. G., Ali, K. N., \& Abdullah, M. N., 2015, p. 15).

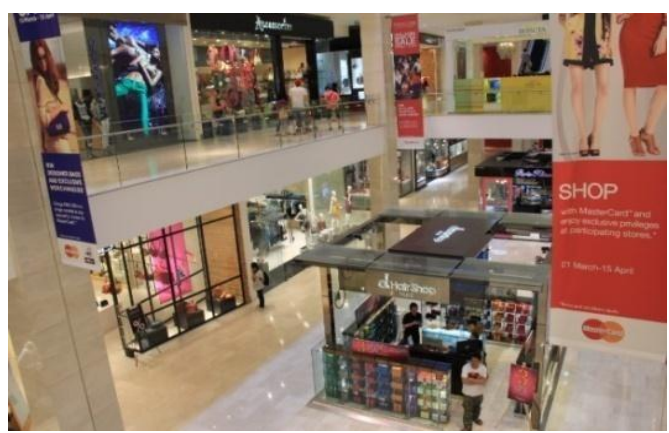

Figure 1. Sufficient space for consumer, example of one of the side views where all the retail shops are in Suria KLCC, Kuala Lumpur.

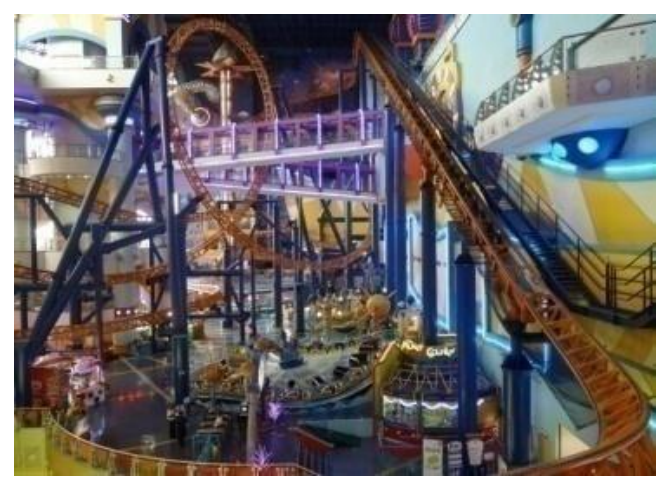

Figure 2. Recreational service provided by shopping malls to attract people in Berjaya Times Square Kuala Lumpur.

The injection of new concept of malls towards the concept of customer friendly with the upgrading of the facilities and infrastructure mainly in providing the elements of entertainment and excitement ( Figure 1) which have become more relevant. It is purposely designed to attract more customers and keep them in the malls. As an example Pavilion, located in the cen- ter of business of Kuala Lumpur, Malaysia, featuring over 450 shops spread across seven levels, this mall covers 1.37 million square feet. In addition Pavilion offers some of the world's most luxurious brands for discerning shoppers. It is also a hub of urban activity including a mix of fitness centre karaoke, cinema, bis- tros and more. The whole complex comprises interna- tional hotels, high-rise offices and shopping mall (Asia-Pacific report, (n.d), p. 23).

Meanwhile, The Mines Shopping Complex, Sun- way Pyramid and Berjaya Times Square are some of the examples of shopping malls which offer the inte- gration of entertainment and recreational space in the shopping malls. Furthermore, with government sup- port in accordance with Malaysia's Vision 2020 to make Kuala Lumpur the center for shopping hub.

In the context of Malaysian consumers, as men- tion by Yusniza K., Chee Lih, Frankie Lee (2010) ear- lier, that Malaysian shoppers are movivated to visit mall in reason they fascinate about the ambience, in- terior of the malls, ease access and also the promo- tional conducted by the malls organizer. In addition, as stated by Paynter, J., \& Lim, J. (2001, p. 8) men- tion: The majority of buyers like to do brick-an mortar shopping, for Malaysian people. One of the shopping malls located in Kuala Lumpur, Suria Mall has 
450,000 visitors per week. To visit a shopping mall has become a kind of Malaysian "weekend activity"; it is a method for some Malaysians to release pressure or spend time with family and friends. They may not necessarily go there to buy anything; it could be for various services that are available in shopping com- plexes like salons, movies, and bowling alleys. (Figure 3).

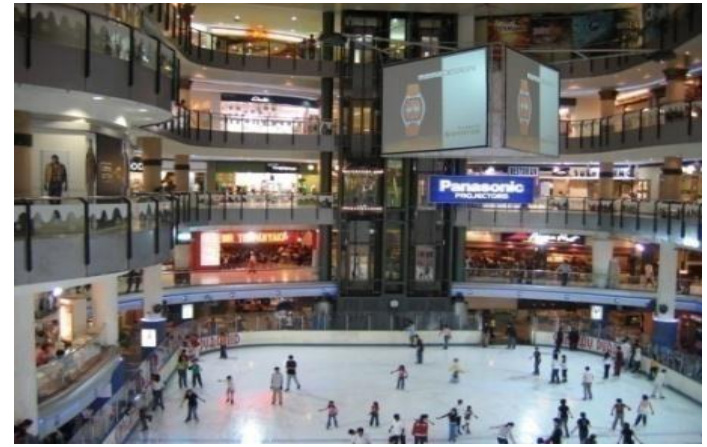

Figure 3. Sunway Pyramid one of the major shopping malls located in Kuala Lumpur equip with most of the facilities from retail shop until to recreational space such ice skating.

There are another several previous research con- ducted, according to Association for Shopping and Highrise Management found that "one in five Malay- sians have spent the weekends in shopping malls" (Price Waterhouse Coopers, 2005/2006 as cited in Wong, Y. T., \& Osman, S. 2013, p. 505 ) and the ma- jority of Malaysian students, especially in urban ar- eas, go shopping at least once every two weeks as the main recreational activity. In fact, this group of people spends more time on shopping compared to Western- ers (Hassan, H., Rahman, M. S., \& Sade, A. B. 2014, p. 62). Urban communities look at their environment as a serious aspect in determining their social life- style. Shopping malls and stores are considered as part of the favorite places for urban people. Those lo- cations are the places which represent the physical and spiritual attributes for each individual.

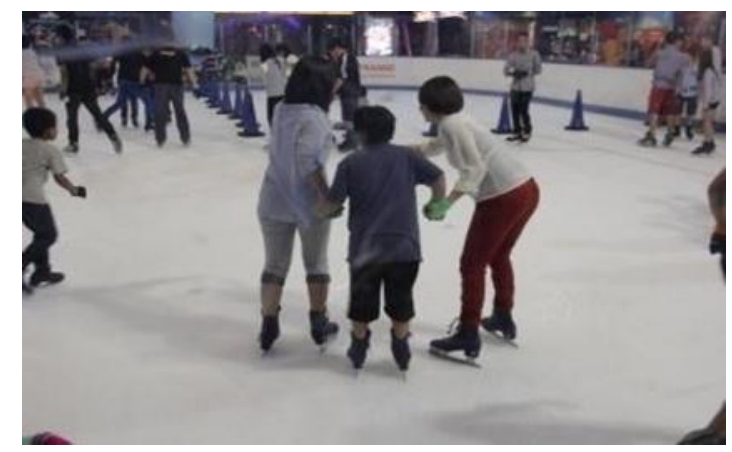

Figure 4. Malaysian consumer enjoying the recreational service - ice skating provided in Sunway Pyramid shopping malls Kuala Lumpur as a part of nowadays lifestyle.

Malls in short could represent the consumer life style and social interaction by stimulating the related activities (figure 4). Furthermore, through shopping malls, the space for buying and selling transaction be- comes more active, portraying how urban people ex- press their obsession and enthusiasm towards ful- filling personal satisfaction.

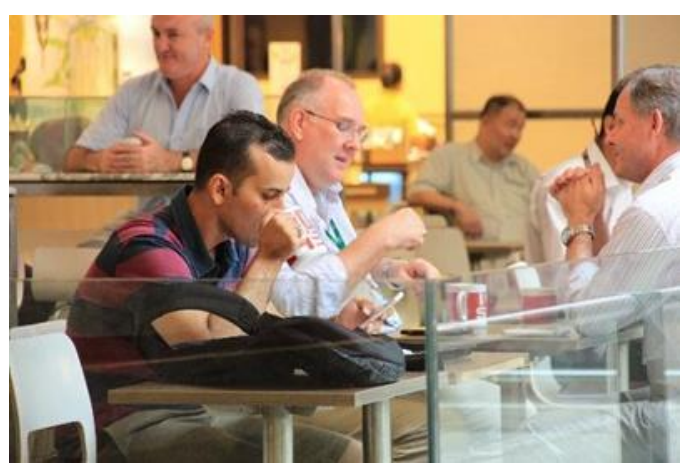

Figure 5. Suria KLCC, shopping malls accomodate with coffee house giving the visitors space for relaxation and it's became as everydays culture lifestyle to urban peoples.

Shopping malls could became silent indicators of the culture development in the urban areas. Malls full with infrastructure provide possibilities in transferring the image of culture to the community, locally or internationally. Moreover, all the latest and newest products or commodities spread to the society through shopping malls and consumerism activities. The capability of malls in fulfilling the satisfaction of urban consumers' desire is significant to mall owners to equip all their spaces in accord- ance with peoples' needs (Figure 5). Nowadays, shopping malls can be considered as platforms in constructing, changing, adapting and showing a so- cial lifestyle among urban people through the me- dium of clothing, foods, goods, and many more which can be found in the malls. Mike Featherstone (1991), stated that lifestyle is a part of "One's body, clothes, speech, leisure pastimes, eating and drink- ing preferences, home, car, choice of holidays, etc. are to be regarded as indicators of the individuality of taste and sense of style of the owner/consumer" (p. 83), Therefore, it's strong indicators that the ability of shopping malls provide and cater the urban society needs and desire conscious and uncon- sciously effected the way of urban society life in form of physical and spiritual. (Figure 6). Lifestyle has definitely been shaped by the institution and so- cial culture within it, and the main concern in trans- ferring and submitting the culture could be collected from the consumption and consumerism activities.

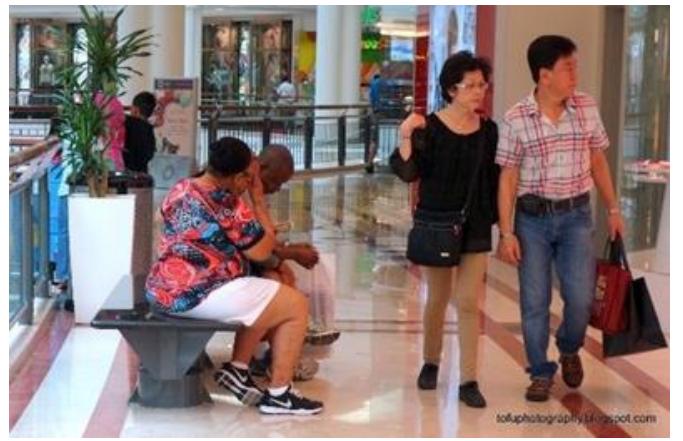

Figure 6. Shopping malls is a space for shopping, leisure, relax- ing or meeting among city people and it's a part of everyday lifestyle or activities for urban society. 


\section{Conclusion}

In conclusion, materialism and consumerism can be considered as two entities which drive the people to fulfill the physical and spiritual desires. Meanwhile, shopping malls within urban environment can be referred to as location whereby the capacity of supply and demand towards consumption of object and ser- vices are in big and massive scale, it contributes to the building of the society at large in forming and constructing urban society identities and personali- ties. The development of urban environments, very much rely on various fact. The economic factors particularly, has open up huge opportunities and po- tential of various parties to join together in promot- ing their economic influences. And yet, cities with shopping malls has become a battlefield for many things highlighted in it, economic, value, cultural, behavioral, and many others eventually end up as mirrors and representation the value of social cul- ture within it. Shopping malls undeniably performs as cultural and economic platforms which contribute in maximizing the value of lifestyle among ur- ban societies and the Malaysian community living around it cannot be separated from this situation. Shopping malls in Malaysian environment is part of platform for cultural unity of the aspect either from the external and internal elements. Hence, shopping malls influence in determining the taste of the pop- ulation to some extent affect people's lifestyle around it. Malaysia again, was not spared from it and it's develop time to time. The lifestyle values in the vicinity of the shopping center can indirectly discovered and identified in the understanding of the people who live around it.

\section{ACKNOWLEDGEMENT(S)}

All the images and information used in this paper are taken from the data based study conducted by researchers from year of 2013 until 2016. About 6 major shopping malls involved in this research namely, Sunway Pyramid, Suria KLCC, Berjaya Time Square, Mid-Valley, One-Utama and Pavillion.

\section{REFERENCES}

[1] Yusniza K. and Chee Lih, Frankie Lee (2010). Attracting shoppers to shopping malls: The Malaysian Perspective. Interdisciplinary Journal of Contemporary Research in Business, 2(3), 185-198.

[2] Erlandson, David A.; Harris, Edward L.; Skipper, Barbara L. \& Allen, Steve D. (1993). Doing naturalistic inquiry: a guide to methods. Newbury Park, CA: Sage.

[3] Dant, T. (1999). Material culture in the social world: values, activities, lifestyles. Open University Press.

[4] Clark, D. (2003). Urban World/Global City, Second Edition. New York: Routledge.

[5] Koch, A. M., \& Elmore, R. (2006). Simulation and Symbolic Exchange: Jean Baudrillard's Augmentation of Marx's Theory of Value. Politics \& Policy, 34(3), 556-575. Retrived
December, $13 \quad 2012$ from, http://libres.uncg.edu/ir/asu/f/Koch_Andrew_2006_Simulation_and_sy mbolic.pdf.

[6] Lloyd, G. (2008). Commodity fetishism and domination: the contributions of Marx, Lukács, Horkheimer, Adorno and Bourdieu (Doctoral dissertation, Rhodes University).

[7] Sheth, J. N., Newman, B. I., \& Gross, B. L. (1991). Consumption values and market choices: Theory and applications (pp. 16-74). South-Western Pub.

[8] Abdallat, M. M. \& El-Emam, H. E. S. (n.d). Consumer Behavior Models in Tourism Analysis Study. Retrieved 2011, from www.faculty.ksu.edu.sa/.

[9] Aliagha, G. U., Qin, Y. G., Ali, K. N., \& Abdullah, M. N. (2015). Analysis of Shopping Mall Attractiveness and Customer Loyalty. Jurnal Teknologi, 74(2).

[10] Hussain, M. Y., Ishak, S., Awang, A. H., Shatir, M. A. A., Lyndon, N., Rose, R. A. C., ... \& Manaf, A. A. (2012). Taburan semasa pusat membeli-belah di Lembah Klang: satu tinjauan awal (Current distribution of shopping centres in the Klang Valley: a preliminary survey. Geografia: Malaysian Journal of Society and Space, 8(8), 130-137

[11] Retrieved on Sept.13 2015, Eye on Asia in 2009, from http://www.grey.com/assets/02/025fc2897c161ca21d0 85b65ad3861004d4634cf.pdf

[12] Paynter, J., \& Lim, J. (2001). Drivers and Impediments to E-commerce in Malaysia. Malaysian Journal of Library \& Information Science, 6(2), 1-19.

[13] Wong, Y. T., \& Osman, S. (2013). Personal Characteristics and Hedonic Shopping Orientation on Apparel Adult Shoppers' Repatronage Behavioral Intention. Journal of Economics and Behavioral Studies, 5(8), 505.

[14] Hassan, H., Rahman, M. S., \& Sade, A. B. (2014). Shopping day and time preferences of Malaysian hypermarket consumers. Australian Journal of Business and Economic Studies 1(1) 61-68.

[15] Featherstone, M. (2007). Consumer culture and postmodernism. London: Sage Publication. 